\title{
Predictors of Late Presentation for HIV/AIDS in West Arsi Zone Public Health Institutions, South Ethiopia: Unmatched Case-Control Study
}

\author{
Sisay Degno (D) \\ Daniel Atlaw $\mathbb{D}^{2}$ \\ Ashenafi Mekonnen ${ }^{3}$ \\ Bikila Lencha ${ }^{\prime}{ }^{\prime}$ \\ Kebede Kumsa' \\ Yohannes Tekalegn (1D) \\ Gashaw Walle (iD) ${ }^{4}$ \\ Ashebir Niggussie ${ }^{5}$ \\ Rameto Aman (ID) \\ 'Department of Public Health, Madda \\ Walabu University, Shashemene, Oromia, \\ Ethiopia; ${ }^{2}$ Department of Human \\ Anatomy, Madda Walabu University, \\ Goba, Oromia, Ethiopia; ${ }^{3}$ Department of \\ Midwifery, Madda Walabu University, \\ Shashemene, Oromia, Ethiopia; \\ ${ }^{4}$ Department of Biomedical Science \\ (Human Anatomy), College of Health \\ Sciences, Debre Tabor University, Debre \\ Tabor, Ethiopia; ${ }^{5}$ Department of \\ Anesthesia, Negelle Arsi General \\ Hospital Medical College, Nagelle, \\ Oromia, Ethiopia
}

Correspondence: Daniel Atlaw Email Danielatmwu@Gmail.Com
Background: Late presentation for HIV/AIDS care is defined as individuals newly presenting for HIV/AIDS care with a CD4 count below 350 cells/ $\mu$ l or presenting for care with WHO clinical staging of stage III or IV. Globally, around 21.7 million people living with HIV/AIDS were receiving ART in 2017, with an increase of 2.3 million since 2016. Despite this progress, most people start ART late in their disease progression.

Objective: This study aims to identify predictors of late presentation for HIV/AIDS among people living with HIV and attending ART clinics in West Arsi Zone public health institutions, South Ethiopia, 2019.

Methodology: A facility-based unmatched case-control study was conducted among people living with HIV attending ART clinics in West Arsi Zone public health institutions, with a total sample size of 500 (167 cases and 333 controls). The sample size was calculated using Epi info version 7 and participants were selected using the case-based control selection sampling technique. Descriptive statistics were carried out to summarize the data. Bi-variate binary logistic regression analysis was carried for selecting candidate variables for multivariate binary logistic regression. A p-value of $<0.05$ was taken to declare the presence of a statistical association between outcomes and explanatory variables.

Results: Rural residence ( $\mathrm{AOR}=7.7495 \% \mathrm{CI}(3.4-17.6)$ ), being single (AOR $=0.1895 \% \mathrm{CI}$ (0.06-0.49)) symptom(s) at first HIV diagnosis (AOR=7.69 95\% CI (4.09-14.4)), no private house $(\mathrm{AOR}=5.0995 \% \mathrm{CI}(2.47-10.45))$, fear of losing job (AOR=4.12 95\% CI $(2.04$ $8.31)$ ), alcohol consumption ( $\mathrm{AOR}=4.3595 \% \mathrm{CI}(2.18-8.69)$, and having chronic medical illness $\quad(\mathrm{AOR}=5.04 \quad 95 \%$ CI $(2.48-10.24))$ were identified as having significant associations with late presentation of HIV/AIDS care.

Conclusion: Rural residence, fear of losing a job, and chronic medical illness were potential risk factors for late presentation of HIV/AIDS care. Being single is the only protective factor for the late presentation of HIV/AIDS care.

Keywords: late presentation, HIV/AIDS care, West Arsi Zone

\section{Background}

Late presentation for HIV/AIDS care is defined as the enrollment of individuals for HIV/AIDS care with a CD4 count below 350 cells/ $\mu$ L. ${ }^{1-3}$ According to the World Health Organization (WHO), HIV clinical staging late presentation is defined as patients presenting for care with Stage III or IV. ${ }^{4}$

Globally, more than 36.9 million people were living with HIV at the end of 2017 (including 1.8 million children), although the distribution varies considerably from country to country and region to region. ${ }^{5,6}$ Most people living with HIV/AIDS are 
found in low- and middle-income countries, out of which around 22.5 million people are living in sub-Saharan Africa. $^{7,8}$ In Ethiopia, more than 39,000 people were newly infected with HIV/AIDS, there were 28,650 HIV/ADS-related deaths, and 76,8040 people were living with HIV/AIDS in 2015. . $^{2}$

In the world, late presentation for HIV/AIDS care is found to be a public health problem. In 2010, overall prevalence of late presentation for HIV/AIDS care in Europe was around 50\% whereas it was around $72 \%$ in Asia. ${ }^{8,10}$ In Africa, the prevalence of late presentation for HIV/AIDS care was estimated to be between 35 and $65 \%{ }^{11}$ In Ethiopia prevalence of late presentation for HIV/AIDS care was around 52.89\%, ranging from $34.4 \%$ in South Ethiopia to $67.7 \%$ in Oromia. ${ }^{12}$

Late presentation for HIV/AIDS is associated with a range of both short- and long-term consequences, like poor treatment outcomes, early development of opportunistic infections, increased health care costs, ART (antiretroviral therapy) drug resistance, and early mortality. ${ }^{4,13-16}$ On the other hand, HIV-infected individuals who present late for care are also more likely to transmit the infection to healthy individuals as a result of serostatus unawareness. $^{3}$ Similarly, the economic costs of HIVpositive individuals who present late for HIV/AIDS care are large as compared to the early presenters. ${ }^{4,15,17,18}$

Several factors may contribute to increasing rates of late presentation for HIV/AIDS care, including socioeconomic and demographic factors like older age, not having a permanent house, and lower education. ${ }^{4,19}$ Further, behavioral factors like alcohol users, having two or more sexual partners, injecting drug users, and non-condom use were significantly associated with late presentation for HIV/AIDS care. ${ }^{7,20,21}$ Similarly, fear of stigma, the presence of symptoms at the time of HIV diagnosis, having a chronic illness, and getting tested by VCT (voluntary counseling and testing) were also associated with late presentation to HIV/AIDS care. ${ }^{20,21}$ Despite significant investment to increase awareness concerning HIV care, many HIV patients still present late for HIV/AIDS care. ${ }^{22}$ Therefore, to reduce the late presentation for HIV care efforts should focus on screening of patients with risk factors for having HIV infection when they are still asymptomatic. ${ }^{19}$

Early presentation for HIV/AIDS care is considered as one of the most effective approaches to reduce the risk of HIV transmission, poor prognosis, and health care costs. ${ }^{23,24}$ Even though different approaches have been used to increase population awareness, late presentation for HIV/AIDS care is still a major problem in Ethiopia. Addressing different predictors of late presentation for HIV/AIDS care is essential to target interventions aimed at favoring early presentation for care. ${ }^{12}$

Even though various studies have been conducted on the various forms of late presentation for HIV/AIDS care in the developing countries and a few parts of Ethiopia, there is limited information on predictors of late presentation for HIV/AIDS care in West Arsi Zone. Therefore, this study aimed to assess predictors of late presentation for HIV/AIDS care in the West Arsi Zone health institution. Early initiation of ART is important for the improvement of HIV/AIDS prevention and control programs.

\section{Materials and Methods}

\section{Study Area and Period}

The study was conducted in the West Arsi Zone public health institutions which are in Oromia Regional State, 250 $\mathrm{km}$ from Addis Ababa, the capital city of Ethiopia. Based on the data obtained from the West Arsi Zone health office, the zone has 7 governmental hospitals, 3 private hospitals, 84 functional health centers, and 48 private clinics. Public health institutions included in the study are Shashamene comprehensive and specialized hospital, Dodola general hospital, Kokosa general hospital, Abosto health center, Nagelle Arsi health center, and Adaba health center, Data were collected from respective public health institutions from October 30 to December 20, 2020 G.C. According to the West Arsi Zone health office report, the zone has a total population of about $2,507,643$.

\section{Study Design and Population}

A facility-based unmatched case-control study was conducted among HIV-positive individuals attending ART clinics at West Arsi Zone public health facilities. All adult HIV-positive individuals attending ART clinics at West Arsi Zone public health facilities were the source population.

\section{Exclusion Criteria}

HIV-positive individuals whose CD4 count within six months of diagnosis or WHO clinical stage were not recorded at first visit were excluded from the study.

\section{Sample Size}

The sample size was calculated using Epi Info ${ }^{\mathrm{TM}}$, version 7 , considering variable fear of disclosure since it provides a maximum sample size. The following assumptions have been taken into consideration: $15 \%$ exposure among controls, 1:2 cases to control ratio, odds ratio of two, $80 \%$ 
power, and 95\% confidence level. Based on the above assumptions, a total of 544 (181 cases and 363 controls) participants were considered for the study.

\section{Sampling Procedure}

First, HIV-positive individuals were classified into two groups based on either CD4 count or WHO clinical HIV staging at the time of the first presentation to the ART clinics. Based on the ART client load in each public health facility, the total sample size was allocated proportionally to each hospital and health center. A case-based control selection technique was employed, as two controls were taken for each case recruited for the study using a simple random sampling technique by taking their arrival order as a sampling frame.

\section{Data Collection Procedure and Tools}

The primary data were collected by using a pre-tested interview administered questionnaire. Data were collected by a trained health professional working on ART. The questionnaire was adapted from different literature and modified to the current aim of the study. The questionnaire was first developed in English and translated into Afan Oromo (local language) by two independent translators to make sure the questions were clear and consistent. The patients' charts were reviewed to retrieve medical information, CD4, and WHO clinical staging of the patients. The contents of the questionnaires included sociodemographic characteristics, HIV testing, and behavioral factors such as the use of alcohol, knowledge, stigma, and attitude towards HIV/AIDS. The quality of data was assured by applying a properly designed and pre-tested questioner. Regular supervision and follow-up were made by the supervisor. In addition, regular check-ups for completeness and consistency of the data were made on a daily basis.

\section{Data Analysis Methods}

The collected data were checked, coded, entered into Epi Info $^{\mathrm{TM}}$, version 7.1, and then exported to SPSS version 25 for further analysis. Then, the entered data were checked for outliers, missing values, and cleaned before data analysis. Descriptive statistics like frequency, mean, and crosstabulation were carried out to summarize data. Binary logistic regression analysis was carried out to check the association of individual variables with the outcome variable. Based on the result of the binary logistic regression analysis, the variables having $\mathrm{p}$-value $<0.2$ in the binary analysis were entered into the multiple logistic regressions model to control the effect of confounders. The Hosmer-Lemeshow goodness-of-fit statistic was used to assess whether the necessary assumptions for the application of multiple logistic regression were fulfilled and $\mathrm{p}$-value 0.32 implyied that the model was fit. Odds ratios (ORs) and the corresponding 95\% confidence intervals (95\% CIs) were calculated for comparison between cases and controls with underlying potential risk factors and for estimating the strength of the associations. Finally, the variables with a p-value less than or equal to 0.05 in multivariate analysis were considered statistically significant.

\section{Ethical Considerations}

This study was conducted in accordance with the Declaration of Helsinki. Ethical clearance was obtained from Madda Walabu University's ethical review committee and the supportive letter was submitted to hospitals and health centers. Informed written consent, which was approved by the ethical review committee of the university, was taken from each patient before an interview. Confidentiality was maintained by omitting any personal identification from the questionnaire and, instead, a code was used. The collected data were used only for research purposes.

\section{Operational Definition}

Cases were HIV-positive individuals newly presenting for care with baseline CD4 counts of $<350 / \mathrm{uL}$ or WHO clinical stages III or IV. ${ }^{12}$

Controls were HIV-positive individuals newly presenting for care with baseline CD4 counts of $\geq 350 / \mathrm{uL}$ or $\mathrm{WHO}$ clinical stages I or II. ${ }^{4}$

\section{Results}

\section{Sociodemographic Characteristics of Study Participants}

From 544 ART clients recruited, 500 of the respondents (167 cases and 333 controls) participated in the study, with a response rate of $92 \%$. Out of 500 respondents, $58 \%$ were female and the mean age of the controls and cases were 33.97 and 38.84 with the standard deviation of 8.8 and 9.6, respectively. Regarding the educational status, majority of cases, 58 (34.7\%), and controls, 132 (39.6\%), had attended primary school. About $68.9 \%$ cases and $82.9 \%$ of controls were urban residents. About $51.5 \%$ of cases and $31.2 \%$ of controls had no HIV care attendant (Table 1). 
Table I Sociodemographic Characteristics of the Study Participants in West Arsi Zone Health Institution, South Ethiopia, 2020

\begin{tabular}{|c|c|c|c|}
\hline Variables & & Cases (167) & Controls (333) \\
\hline \multirow[t]{6}{*}{ Age $(n=500)$} & $<20$ years & $2(1.2 \%)$ & $13(3.9 \%)$ \\
\hline & $20-29$ years & $21(12.6 \%)$ & $82(24.6 \%)$ \\
\hline & $30-39$ years & $62(37.1 \%)$ & $160(48 \%)$ \\
\hline & $40-49$ years & $60(35.9 \%)$ & 57 (I7.1\%) \\
\hline & $50-59$ years & 17 (I0.2\%) & 15 (4.5\%) \\
\hline & $>60$ years & $5(3 \%)$ & $6(1.8 \%)$ \\
\hline \multirow[t]{2}{*}{ Sex } & Male & $80(47.9 \%)$ & $130(39.03)$ \\
\hline & Female & $87(52.1 \%)$ & $203(60.97)$ \\
\hline \multirow[t]{5}{*}{ Educational status } & Illiterate & $4 \mid(24.6 \%)$ & $76(22.8 \%)$ \\
\hline & Only reading and writing & $26(15.6 \%)$ & 47 (14.1\%) \\
\hline & Primary school & $58(34.7 \%)$ & $132(39.6 \%)$ \\
\hline & Secondary school & $36(21.6 \%)$ & $59(17.7 \%)$ \\
\hline & College and above & $6(3.6 \%)$ & $19(5.7 \%)$ \\
\hline \multirow[t]{4}{*}{ Marital status } & Married & 70 (4I.9\%) & $177(53.2 \%)$ \\
\hline & Single & $19(44.1 \%)$ & $54(16.2 \%)$ \\
\hline & Divorced & $30(18 \%)$ & $60(18 \%)$ \\
\hline & Widowed & $48(28.7 \%$ & 42 (I2.6\%) \\
\hline \multirow[t]{2}{*}{ Residence } & Urban & 115 (68.9\%) & $276(82.9 \%)$ \\
\hline & Rural & $52(31.1 \%)$ & $57(21.1 \%)$ \\
\hline \multirow[t]{6}{*}{ Occupation } & Housewife & $28(16.8 \%)$ & 83 (24.9\%) \\
\hline & Farmer & $21(12.6 \%)$ & $41(12.3 \%)$ \\
\hline & Merchant & $40(24 \%)$ & $65(19.5 \%)$ \\
\hline & Daily labourer & 38 (22.8\%) & $94(28.2 \%)$ \\
\hline & Government employee & $20(12 \%)$ & $27(8.1 \%)$ \\
\hline & Other & $20(12 \%)$ & $23(6.9 \%)$ \\
\hline \multirow[t]{2}{*}{ Presence of under 5 children in the home } & Yes & $238(71.5 \%)$ & $113(67.7 \%)$ \\
\hline & No & 95 (28.5\%) & $54(32.3 \%)$ \\
\hline
\end{tabular}

\section{Behavioral and Other Related Characteristics of the Study Participants} Most of the cases and controls acquired HIV infection through heterosexual intercourse. On the other hand, more than half of the cases had a history of alcohol intake (Table 2).

\section{HIV/AIDS Testing and Related Factors}

Most of the cases and controls had got both post- and pretest counseling. Around $50.3 \%$ of cases and $1.6 \%$ of controls had a history of chronic illness (Table 3).

\section{Predictors of Late Presentation}

On binary logistic regression, marital status, residence, occupation, not having a private house, absence of under 5 children at home, year of ART start, absence of HIV care attendance, fear of losing a job, not knowing the mode of HIV acquisition, ever used alcohol, cigarette smoking, chronic medical problem, fear of disclosure, fear of stigma, and presence of HIV-related symptoms at first diagnosis were found to be associated with late presentation for HIV/AIDS care. These factors were included in the multiple logistic regression analysis, and variables which were significantly associated with late presentation for HIV care at 0.05 level of significance were being single, rural residence, not having a private house, fear of losing a job, ever used alcohol, presence of HIV-related symptoms at first diagnosis, chronic medical problem, and fear of stigma (Table 4).

HIV-positive individuals who were single were $82 \%$ less likely to present late for HIV/AIDS care as compared to married individuals (AOR=0.0.18 95\% CI $(0.06-0.49)$ ). Similarly, HIV-positive individuals who live in rural areas were about 8 times more likely to present late for HIV/AIDS care as compared to those living in urban areas $(\mathrm{AOR}=7.74$ 95\% CI (3.4-17.6)). HIV-positive individuals who have no 
Table 2 Behavioral and Other Related Characteristics of the Study Participants, West Arsi Zone Public Institution, South Ethiopia, 2020

\begin{tabular}{|c|c|c|c|}
\hline Variables & & Cases (167) & Controls (333) \\
\hline \multirow[t]{2}{*}{ Fear of losing a job } & Yes & $69(41.3 \%)$ & $300(90.1 \%)$ \\
\hline & No & 98 (58.7\%) & $33(29.9 \%)$ \\
\hline \multirow[t]{3}{*}{ Mode of acquiring HIV } & Heterosexual & 118 (70.7\%) & 266 (79.9\%) \\
\hline & Homosexual & $2(1.2 \%)$ & II (3.3\%) \\
\hline & I do not know & 47 (28.1\%) & $56(16.8 \%)$ \\
\hline \multirow[t]{2}{*}{ Ever using alcohol } & Yes & 89 (53.3\%) & $72(21.6 \%)$ \\
\hline & No & 78 (46.7\%) & $26 \mid(78.4 \%)$ \\
\hline \multirow[t]{2}{*}{ Ever chewing chat } & Yes & 48 (28.7\%) & $72(21.6 \%)$ \\
\hline & No & $119(71.3)$ & 261 (72.4\%) \\
\hline \multirow[t]{2}{*}{ Ever smoking cigarettes } & Yes & $36(72.4 \%)$ & $43(12.9 \%)$ \\
\hline & No & $|7|(2 \mid .6 \%)$ & $290(87.1 \%)$ \\
\hline \multirow[t]{2}{*}{ Ever smoking shisha } & Yes & $4(2.4 \%)$ & $16(4.8 \%)$ \\
\hline & No & $163(97.6 \%)$ & 317 (65.2\%) \\
\hline \multirow[t]{2}{*}{ Presence of HIV care attendance } & Yes & 81 (48.5\%) & $229(68.8 \%)$ \\
\hline & No & $86(51.5 \%)$ & $104(31.2 \%)$ \\
\hline \multirow[t]{4}{*}{ Year of ART start } & Before 2016 & $103(61.7 \%)$ & $124(37.2 \%)$ \\
\hline & $2016-2017$ & $18(10.8 \%)$ & $63(18.9 \%)$ \\
\hline & $2018-2019$ & 39 (23.4\%) & $125(37.5 \%)$ \\
\hline & 2020 & 7 (4.2\%) & $21(6.3 \%)$ \\
\hline \multirow[t]{3}{*}{ Travel time to clinic } & $<0.5$ hour & 89 (53.3\%) & 190 (57.1\%) \\
\hline & $0.5-2$ hour & 55 (32.9\%) & 109 (32.7\%) \\
\hline & $>2$ hour & 23 (13.8\%) & 34 (10.2\%) \\
\hline
\end{tabular}

private house were about 5 times more likely to present late for care $(\mathrm{AOR}=5.095 \% \mathrm{CI}(2.47-10.45))$. The results also showed that the odds of late presentation for HIV/AIDS care among those with symptom(s) at first HIV diagnosis were about 7.69 (AOR=7.69 95\% CI (4.09-14.4). On the other hand, HIV-positive individuals who reported fear of losing their job were 4 times more likely to present late for HIV/ AIDS care $(\mathrm{AOR}=4.12,95 \%$ (2.04-8.31)). Furthermore, alcohol users were about 4 times more likely to present late as compared to non-alcohol users $(\mathrm{AOR}=4.13,95 \% \mathrm{CI}$ (2.18-8.69)). Individuals who had a chronic medical illness were about 5 times more likely to present late as compared to those without a chronic medical illness ( $\mathrm{AOR}=5.05,95 \% \mathrm{CI}$ (2.48-10.24)). Similarly, individuals who reported fear of stigma were 3 times more likely to present late $(\mathrm{AOR}=3.49,95 \%$ CI (1.91-6.29) (Table 4).

\section{Discussion}

Early initiation of ART was found to be very crucial for better health outcomes for HIV-positive individuals on ART. It also helps to strengthen actions taken to prevent transmission of the infection, particularly from those who are unaware of their serostatus. However, the decision to initiate ART early is significantly associated with various social, service-related, and contextual factors. This study investigated predictors of late presentation for HI/AIDS care in West Arsi Zone public health facilities, Oromia regional state, Ethiopia.

Accordingly, the residence of ART clients was found to have a significant association with late presentation for HIV/AIDS care. Study participants who live in rural areas were about 8 times more likely to present late for HIV/AIDS care as compared to those living in urban areas (AOR=7.74 95\% CI (3.4-17.6)). The result is consistent with study findings in South Africa. ${ }^{25}$ This could be explained by the fact that individuals of rural residence are less likely to get the updated information when compared with those in urban residences. In addition, limited accessibility of health institutions and less health careseeking behavior of rural residents might contribute to the observed finding. 
Table 3 HIVIAIDS Testing and Related Factors Characteristics of the Study Participants in West Arsi Zone Public Institution, South Ethiopia, 2020

\begin{tabular}{|c|c|c|c|}
\hline Variables & & Cases (167) & Controls (333) \\
\hline \multirow[t]{2}{*}{ Perception that HIV is curable } & Yes & $56(33.5 \%)$ & 98 (29.4\%) \\
\hline & No & III (66.5\%) & 235 (70.6\%) \\
\hline \multirow[t]{2}{*}{ Perception that HIV is preventable } & Yes & $162(97 \%)$ & $312(93.7 \%)$ \\
\hline & No & $5(3 \%)$ & $21(6.3 \%)$ \\
\hline \multirow[t]{2}{*}{ Symptoms at first HIV diagnosis } & Yes & II 5 (68.9\%) & $62(18.6 \%)$ \\
\hline & No & $52(31.1 \%)$ & $271(81.4 \%)$ \\
\hline \multirow[t]{2}{*}{ Chronic illness } & Yes & $84(50.3 \%)$ & $6(1.8 \%)$ \\
\hline & No & $83(49.7)$ & 327 (97.2\%) \\
\hline \multirow[t]{2}{*}{ Pre-testing counseling } & Yes & $160(95.8 \%)$ & $313(94 \%)$ \\
\hline & No & $7(4.2 \%)$ & $20(6 \%)$ \\
\hline \multirow[t]{2}{*}{ Fear of disclosure } & Yes & $142(85 \%)$ & $216(64.9 \%)$ \\
\hline & No & $25(15 \%)$ & $117(35.1 \%)$ \\
\hline \multirow[t]{2}{*}{ Fear of stigma } & Yes & $88(52.6 \%)$ & $95(25.5 \%)$ \\
\hline & No & 79 (47.4\%) & $278(74.5 \%)$ \\
\hline
\end{tabular}

Table 4 Logistic Regression Analysis of Predictors of Late Presentation for HIV/AIDS Care in West Arsi Zone Public Institution, South Ethiopia, 2019

\begin{tabular}{|c|c|c|c|c|c|c|}
\hline Variables & & Cases (167) & Controls (333) & COR $(95 \% \mathrm{Cl})$ & AOR $(95 \% \mathrm{Cl})$ & p-value \\
\hline Marital status & $\begin{array}{l}\text { Married } \\
\text { Single } \\
\text { Divorced } \\
\text { Widowed }\end{array}$ & $\begin{array}{l}70 \\
19 \\
30 \\
48\end{array}$ & $\begin{array}{l}177 \\
54 \\
60 \\
42\end{array}$ & $\begin{array}{l}\mathrm{I} \\
0.86(0.49-1.6) \\
\mathrm{I} .26(0.75-2.12) \\
2.89(1.75-4.75)\end{array}$ & $\begin{array}{l}\mathrm{I} \\
0.18(0.06-0.49) \\
0.54(0.22-1.34) \\
0.98(0.39-2.41)\end{array}$ & $\begin{array}{l}0.001 \\
0.18 \\
0.98\end{array}$ \\
\hline Residence & $\begin{array}{l}\text { Urban } \\
\text { Rural }\end{array}$ & $\begin{array}{l}105 \\
62\end{array}$ & $\begin{array}{l}291 \\
42\end{array}$ & $\begin{array}{l}\text { I } \\
4.09(2.6-6.4)\end{array}$ & $\begin{array}{l}\text { I } \\
7.74(3.4-17.6)\end{array}$ & $0.001 *$ \\
\hline Private house & $\begin{array}{l}\text { Yes } \\
\text { No }\end{array}$ & $\begin{array}{l}42 \\
125\end{array}$ & $\begin{array}{l}171 \\
162\end{array}$ & I $2.82(1.87-4.25)$ & $\begin{array}{l}\text { I } \\
5.09(2.47-10.45)\end{array}$ & $0.001 *$ \\
\hline Fear of losing a job & $\begin{array}{l}\text { Yes } \\
\text { No }\end{array}$ & $\begin{array}{l}69 \\
98\end{array}$ & $\begin{array}{l}300 \\
33\end{array}$ & $\begin{array}{l}6.4(3.98-10.27) \\
\text { I }\end{array}$ & $\begin{array}{l}4.12(2.04-8.31) \\
I\end{array}$ & $0.001 *$ \\
\hline Ever used alcohol & $\begin{array}{l}\text { Yes } \\
\text { No }\end{array}$ & $\begin{array}{l}52 \\
115\end{array}$ & $\begin{array}{l}89 \\
244\end{array}$ & $\begin{array}{l}4.1(2.7-6.1) \\
1\end{array}$ & $\begin{array}{l}4.35(2.18-8.69) \\
\text { I }\end{array}$ & $0.001 *$ \\
\hline Symptoms at first HIV diagnosis & $\begin{array}{l}\text { Yes } \\
\text { No }\end{array}$ & $\begin{array}{l}115 \\
52\end{array}$ & $\begin{array}{l}62 \\
271\end{array}$ & $\begin{array}{l}9.58(6.24-|4.7|) \\
I\end{array}$ & $\begin{array}{l}7.69(4.09-14.4) \\
1\end{array}$ & $0.001 *$ \\
\hline Chronic illness & $\begin{array}{l}\text { Yes } \\
\text { No }\end{array}$ & $\begin{array}{l}77 \\
90\end{array}$ & $\begin{array}{l}9 \\
324\end{array}$ & $\begin{array}{l}\text { II.47 (6.97-I8.85) } \\
\text { I }\end{array}$ & $\begin{array}{l}5.04(2.48-10.24) \\
\text { I }\end{array}$ & $0.001 *$ \\
\hline Fear of stigma & $\begin{array}{l}\text { Yes } \\
\text { No }\end{array}$ & $\begin{array}{l}88 \\
79\end{array}$ & $\begin{array}{l}95 \\
238\end{array}$ & $\begin{array}{l}2.79(1.89-4.1) \\
1\end{array}$ & $\begin{array}{l}3.49(1.91-6.29) \\
1\end{array}$ & $<0.001 *$ \\
\hline
\end{tabular}

Note: *Significant.

In this study, ART clients with symptom(s) at first HIV diagnosis were 8 times more likely to present late for HIV/ AIDS care as compared with ART clients without symptom(s) at first HIV diagnosis (AOR=7.69, 95\% CI (4.09-14.4)). A similar finding was reported by the studies conducted in southwest and northwest Ethiopia. ${ }^{13,26}$ The possible reason for 
the observed result could be that people living with HIV/AIDS presenting late in the course of their disease were more likely to be diagnosed at advanced stages of disease progression.

The other variable found to be a significant predictor for late presentation for HIV/AIDS care was the status of having a private house. The odds of late presentation for HIV/AIDS care among individuals who have no private house is higher compared with their counterparts $(\mathrm{AOR}=5.09,95 \% \mathrm{CI}(2.47-$ $10.45)$ ), which is in line with the results of studies conducted in Ethiopia. $^{26}$ Late presentation for HIV/AIDS care is higher among study participants who consumed alcohol as compared with those who responded as not consuming alcohol ever (AOR=4.35, 95\% CI (2.18-8.69)). Similar findings were reported by studies conducted in Ethiopia. ${ }^{13,26}$ It can be explained by the fact that individuals who consume alcohol have low health care-seeking behaviors.

Furthermore, the finding of this study shows that HIVpositive individuals who reported fear of losing a job were more likely to present late for HIV/AIDS care. This is in line with a study done in Southern Tigray Zone, Ethiopia. ${ }^{27}$ Even if HIV-positive individuals have good HIV risk perception, due to fear of losing their job if they are found to be positive for the virus, they are more likely to present late for HIV/AIDS care. Similarly, the odds of late presentation for HIV/AIDS care were significantly higher among ART clients who had a chronic health problem $(\mathrm{AOR}=5.04,95 \%$ CI $(2.48-10.24)$ ) as compared with their counterparts. The possible reason could be that ART patients might fear the possible complication of having HIV and other chronic illnesses, which may influence them to not initiate HIV/AIDS care. The finding is supported by the result of the study done in Birmingham, United Kingdom, where ART clients who had a chronic illness at the time of HIV diagnosis were less likely to present for HIV/ AIDS care earlier as compared with those who did not have a chronic illness.

This study revealed that fear of stigma is significantly associated with late presentation for HIV/AIDS care. ART clients who fear stigma were nearly four times more likely to present late for HIV/AIDS care relative to those who did not fear the stigma associated with being HIV-positive $(\mathrm{AOR}=3.49,95 \% \mathrm{CI}(1.91-6.29))$. Concurrent findings were reported by research conducted in Harare city in Ethiopia and Zimbabwe. ${ }^{4,27}$ The result might be associated with fear of loss of material and/or emotional benefits if serostatus is known in the community.

Finally, this study was reported with a limitation that it is prone to recall bias, as it relied on individual self-report of events that occurred a relatively long time ago.

\section{Conclusion}

In general, rural residence, not having a private house, fear of stigma, fear of losing a job, ever alcohol use, presence of HIV related symptoms at first diagnosis, and a chronic medical illness had a higher probability of presenting late for HIV/AIDS care. On the other hand, being single is the only protective factor for late presentation for HIV/AIDS care.

\section{Recommendation}

Intervention like awareness-raising on the role of early invitation for HIV/AIDS care focusing on alcohol consumers, rural residents and those who do not have a private house needs to be strengthened by health facilities, woreda (districts) and zonal health offices. Routine testing of patients attending chronic health illnesses in health centers and hospitals should be strengthened. Appropriate implementation of index case testing focusing on the rural community, alcohol consumers and married family needs to be kept in place. In addition, a social network strategy on the advantage of early entry into care should be strengthened at all levels.

\section{List of Acronyms/Abbreviations}

AIDS, Acquired Immunodeficiency Syndrome; ANC, Antenatal Care; ART, Antiretroviral Therapy; EDHS, Ethiopian Demographic and Health Survey; HBCT, Home Based Counseling and Testing; HIV, Human Immunodeficiency Virus; PICT, Provider Initiator Counseling and Testing; PLWH, People living with Human immunodeficiency virus; PMTCT, Prevention of Mother to Child Transmission; STI, Sexually transmitted infection; UNAIDS, United Nations Program on HIV/AIDS; VCT, Voluntary counseling and testing; WHO, World Health Organization.

\section{Data Sharing Statement}

The datasets used and analyzed during the current study are available from the corresponding author on reasonable request.

\section{Ethical Approval and Consent to Participate}

The study received ethical approval from the MWU Ethical Review Committee and written informed consent was received from each participant.

\section{Acknowledgment}

We want to express our great thanks to Madda Walabu University. 


\section{Author Contributions}

All authors made a significant contribution to the work reported, whether that is in the conception, study design, execution, acquisition of data, analysis and interpretation, or in all these areas; took part in drafting, revising or critically reviewing the article; gave final approval of the version to be published; have agreed on the journal to which the article has been submitted; and agree to be accountable for all aspects of the work.

\section{Disclosure}

The authors declare that they have no conflicts of interest for this work.

\section{References}

1. Antinori A, Coenen T, Costagiola D, et al. Late presentation of HIV infection: a consensus definition. HIV Med. 1201;12:61-64. doi: $10.1111 / \mathrm{j} .1468-1293.2010 .00857 . \mathrm{x}$

2. Waldrop G. Stable patients and patients with advanced disease: consensus definitions to support sustained scale up of antiretroviral therapy. Trop Med Int Health. 2016;1:1-8.

3. Kozak M. Review Late diagnosis, delayed presentation and late presentation in HIV: proposed definitions, methodological considerations and health implications. Int Med Press. 2013;18:17-23.

4. Nyika H. Factors associated with late presentation for HIV/AIDS care in Harare City, Zimbabwe. BMC Public Health. 2015;16 (369):1-7.

5. UNAIDS. Global HIV and AIDS statistics; 2018.

6. UNAIDS. Global HIV and AIDS statistics; 2017.

7. Beck EJ. The cost-effectiveness of highly active antiretroviral therapy. Canada. 2004;18:2411-2418.

8. Krentz H, Gill M. Cost of medical care for HIV-infected patients within a regional population from 1997 to 2006. HIV Med. 2008;9:721-730. doi:10.1111/j.1468-1293.2008.00613.x

9. Wang H. Estimates of global, regional, and national incidence, prevalence, and mortality of HIV, 1980 - 2015: the Global Burden of Disease Study. Lancet HIV. 2016;3:361-387.

10. Jeong S, Italiano C, Chaiwarith R. Late Presentation into Care of HIV Disease and Its Associated Factors in Asia. AIDS Res Hum Retroviruses.2016;32(3):255-261. doi:10.1089/aid.2015.0058

11. Abebe N. Survival status of HIV positive adults on antiretroviral treatment in Debre Markos Referral Hospital, Northwest Ethiopia: retrospective cohort study. Pan African Med J. 2014;8:1-13.

12. Belay G, Endalamaw A, Ayele A. Late presentation of HIV positive adults and its predictors to HIV/AIDS care in Ethiopia: a systematic review and meta-analysis. BMC Infect Dis. 2019;19(534):1-8.
13. Gesesew H, Ward P, Woldemichael K, et al. Late presentation for HIV care in Southwest Ethiopia in 2003-2015: prevalence, trend, outcomes and risk factors. BMC Infect Dis. 2018;18(19):1-11. doi:10.1186/s12879-018-2971-6

14. Kigozi I. Late disease stage at presentation to an HIV clinic in the era of free antiretroviral therapy in sub-Saharan Africa. J Acquir Immune Defic Syndr. 2010;52(2):1-21.

15. Mocroft A. Risk Factors and Outcomes for Late Presentation for HIV-Positive Persons in Europe: results from the Collaboration of Observational HIV Epidemiological Research Europe Study (COHERE). Plos Med. 2013;10(9).

16. Sobrino-vegas P, Moreno S, Rubio R, et al. Impact of late presentation of HIV infection on short-, mid- and long-term mortality and causes of death in a multicenter national cohort. $j$ Infect. 2016;72:587-596. doi:10.1016/j.jinf.2016.01.017

17. Meyer-rath G, Over M, Bangsberg DR. HIV Treatment as Prevention: modelling the Cost of Antiretroviral Treatment - state of the Art and Future Directions. PLoS Med. 2012;9(7):1-6. doi:10.1371/journal.pmed.1001247

18. Tshabangu N, Mohapi L, Rosen S. NIH Public Access. J Acquir Immune Defic Syndr. 2014;62(3):322-328.

19. Alvarez-uria G. Factors Associated with Late Presentation of HIV and Estimation of Antiretroviral Treatment Need according to CD4 Lymphocyte Count in a Resource-Limited Setting: A cohort study in India. Interdiscip Perspec Infect Dis.. 2016;9(3):1-8.

20. Coul E, van Sighem A, Brinkman K, et al. Factors associated with presenting late or with advanced HIV disease in the Netherlands, 1996 - 2014: results from a national observational cohort. BMJ Open. 2016;6:e09688. doi:10.1136/bmjopen-2015-009688

21. Gesesew H, Tesfamichael F, Adamu B. Factors Affecting Late Presentation for HIV/AIDS Care in Southwest Ethiopia: a Case Control Study. Public Health Res. 2013;3(4):98-107.

22. Darcis G. Factors associated with late presentation for HIV care in a single Belgian reference center; 2018:2006-2017.

23. Krentz H, Gil M. Increased costs of HIV care associated with aging in an HIV-infected population. HIV Med. 2015;16:38-47. doi:10.1111/hiv.12176

24. Hermans L. Delayed HIV testing in internal medicine clinics a missed opportunity. $J$ Med. 2012;70(2):69-73.

25. Fomundam HN. Prevalence and predictors of late presentation for HIV care in South Africa. Sam j. 2017;107(12):1058-1064.

26. Abaynew Y, Deribew A, Deribe K. Factors associated with late presentation to HIV/AIDS care in South Wollo ZoneEthiopia: a case-control study. AIDS Res Ther. 2011;8(8):4-9. doi:10.1186/ 1742-6405-8-8

27. Gelaw YA, Senbete GH, Adane AA, et al. Determinants of late presentation to HIV/AIDS care in Southern Tigray Zone, Northern Ethiopia: an institution based case - control study. AIDS Res Ther. 2015;12(40):1-8. doi:10.1186/s12981-015-0079-2
HIV/AIDS - Research and Palliative Care

\section{Publish your work in this journal}

HIV/AIDS - Research and Palliative Care is an international, peerreviewed open-access journal focusing on advances in research in HIV, its clinical progression and management options including antiviral treatment, palliative care and public healthcare policies to control viral spread. The manuscript management system is completely online and includes a very quick and fair peer-review system, which is all easy to use. Visit http://www.dovepress.com/testimonials.php to read real quotes from published authors. 